\title{
Pd-Catalyzed Direct Alkynylation of Aliphatic C-H Bonds
}

Key words

alkynylation

C-H activation

palladium<smiles>[R]CC(=O)Nc1cccc2cccnc12</smiles>

$\mathrm{R}=$ substituted Alk, $\mathrm{Ar}, \mathrm{CF}_{3}, \mathrm{OMe}$ TIPS = triisopropylsilyl
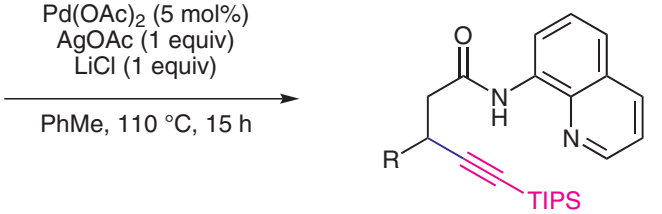

up to $75 \%$ yield

Selected examples:

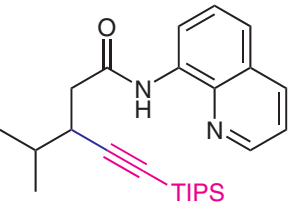

$64 \%$ yield

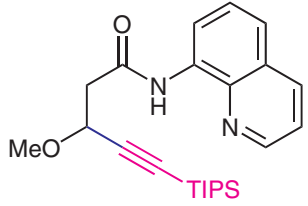

$60 \%$ yield<smiles>CCCCCCC#CC(CC(=O)OC)C(=O)Nc1cccc2cccnc12</smiles>

$60 \%$ yield<smiles>CC#CC(CC(=O)Nc1cccc2cccnc12)c1ccc([N+](=O)[O-])cc1</smiles>

$75 \%$ yield<smiles>CC(C)(C)OC(=O)N(Cc1ccccc1)CC(C#C[18F])CC(=O)Nc1cccc2cccnc12</smiles>

$62 \%$ yield
Significance: The first palladium-catalyzed alkynylation of unactivated $\mathrm{C}\left(\mathrm{sp}^{3}\right)-\mathrm{H}$ bonds in aliphatic carboxylic acid derivatives has been disclosed. 8-Aminoquinoline proved to be the best directing group to promote the desired alkynylation reaction.

\section{Comment: Interestingly, replacement of the} 8-aminoquinoline moiety with a 1-aminonaphthyl group or N-methylation of the amide group completely inhibited the ethynylation reaction, indicating that both, the nitrogen of the quinoline moiety and the $\mathrm{NH}$ group of the amide are essential for the reaction. 